\title{
LVI. The theory of osmotic pressure and its bearing on the nature of solutions
}

\section{Spencer Umfreville Pickering M.A.}

To cite this article: Spencer Umfreville Pickering M.A. (1890) LVI. The theory of osmotic pressure and its bearing on the nature of solutions, Philosophical Magazine Series 5, 29:181, 490-501, DOI: $10.1080 / 14786449008619973$

To link to this article: http://dx.doi.org/10.1080/14786449008619973

Published online: 08 May 2009.

Submit your article to this journal $₫$

Џ Article views: 3

Q View related articles $\square$ 
but here, as in all the above cases, the catalytic agent, by producing a condition of dynamical equilibrium, greatly facilitates the change.

Further instances of the precise similarity between the action of catalytic agents and of those substances which are capable of endowing nonconducting liquids with the power of conduction will doubtless be found, and further proof analogous to those advanced here in the case of stannic chloride of the strict parallelism between the phenomena, of the birth of electrolytic power and of enhanced chemical activity, will trace these effects back to an identity of cause, the setting up of a condition of dynamical equilibrium.

Emmanuel College, Cambridge.

LVI. The Theory of Osmotic Pressure and its bearing on the Nature of Solutions. By Spencer Umfrevilde Pickering, $M . A .^{*}$

NO one can doubt the mathematical correctness of the conclusions which Arrhenius,'van't Hoff, Ostwald, and others draw from the premisses with which they start in their arguments respecting osmotic pressure, nor can we doubt the value of connecting numerous actions with one and the same cause, or that there are a large number of instances in which the observed facts are in substantial agreement with their conclusions. But we may, I think, legitimately doubt whether the premisses of the arguments are sound, whether the conclusions harmonize as well as they should with experimental data, whether the theory is more than a mathematical exercise, or more than a convenient working hypothesis of a rough character, instead of being, as its supporters maintain, an hypothesis established so firmly that we may build upon it a physical theory of solution.

The direct measurement of osmotic pressure has been made in but a few cases, and those cases are ones in which the substances examined are eminently unfitted for showing the presence of any chemical action which may be present. Of the phenomena correlated with osmotic pressure, the lowering of the freezing-point of a solvent by the addition of foreign substances is the one which has received the greatest attention, thanks to Raoult's classical work, and is the one which forms the main support of the theory.

In examining the experimental facts the following questions must be asked, and if the theory is correct they must be answered in the affirmative.

* Communicated by the Physical Society: read Mareh 7, 1890. 
(1) Is the molecular depression-using this term to mean the lowering of the freezing-point produced by one foreign molecule on 100 molecules (not parts by weight) of the solvent -a constant, whatever the foreign substance is, provided that the amount of the latter is not greater than that which would give a pressure equal to that produced by it in the gaseous state at the same temperature?

(2) Are such deviations from regularity, as are observed in exceptional cases, in the direction in which they should be according to the theory?

(3) Is the depression a constant whatever the solvent is?

(4) Is the depression constant when the proportions of the solvent and dissolved substance are varied within the limits mentioned in (1)?

(5) When stronger solutions are taken, is the deviation from regularity in the direction in which it should be according to the theory?

(6) Is the deviation always in the same direction, and always regular?

I believe that I can show that the answer to every one of these questions is an unqualified No.

The main facts of the case as elucidated by Raoult's work are that, when various substances are dissolved in

\author{
Benzene, \\ Nitrobenzene, \\ Ethylene dibromide, \\ Formic acid, \\ or Acetic acid,
}

the molecular depression is about $0^{\circ} 63$, though there are a few substances in each case which give an abnormal depression of about half this amount.

With water the molecular depression is generally $2^{\circ} \cdot 06$, but in many cases approximates to $2^{\circ} \cdot 61$, values which Raoult takes to be three and four times $0^{\circ} .63\left(1^{\circ} .89\right.$ and $\left.2^{\circ} \cdot 52\right)$ respectively. Abnormally low values are in the same proportion to the normal ones as with other solvents; they are about $1^{\circ} .03$ (half of $2^{\circ} .06$ ), and are obtained with some inorganic substances, and with the majority of organic substances at present investigated.

All these determinations apply to solutions containing about 1 molecule to 100 molecules of the solvent, and are, therefore, three or four times stronger than they should be in order to be comparable with gases under ordinary conditions. We shall have to decide whether the discrepancies which they 
show are such as could be reasonably attributed to increasing the pressure from one to three or four atmospheres.

\section{Influence of the Nature of the Dissolved Substance.}

The half values obtained in many cases are explained by the duplication of molecules, owing to the solutions not being sufficiently dilute; that is, an additional pressure of two or three atmospheres will cause the vapour-densities of hydrochloric acid *, methyl, ethyl, amyl, and butyl alcohols $\dagger$, benzol, and many other substances to double themselves (assuming that they retain their gaseous condition). This may be so, but direct determinations cannot be, or have not been, made.

Leaving these abnormal values for the present, we find that the normal ones exhibit the following variations:-

\begin{tabular}{|c|c|c|}
\hline Solvent. & $\begin{array}{l}\text { Number of } \\
\text { instances } \\
\text { in vestigated. }\end{array}$ & $\begin{array}{l}\text { Variation in the value } \\
\text { of the depression } \ddagger \text {. }\end{array}$ \\
\hline Acetic acid ..... & 57 & 30 per cent. \\
\hline 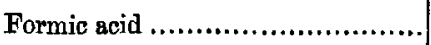 & 9 & $14 "$ \\
\hline Benzene.................................... & 41 & $12 "$ \\
\hline Nitrobenzene & 13 & 7 \\
\hline Ethylene dibromide...................... & 5 & 2 \\
\hline 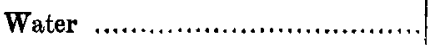 & 59 & $60 \S$, \\
\hline$" \quad$ (with organic substances) & 29 & $40 "$ \\
\hline
\end{tabular}

These variations appear somewhat too large to be attributed to the fact that we are working at two or three more atmospheres of pressure than we should be.

It is noticeable that the organic solvents, except acetic acid, give comparatively constant results, but that, as soon as we come to the inorganic sulvent water (which we know shows a much greater tendency to form "molecular" compounds than the other liquids), we get a much larger variation, and the following values \| will justify the assumption that when other solvents of a similar nature are examined, still greater variations will be observed.

* Solvent, Acetic acid (Rooult, Ann. Chim. Phys. [6] xi. p. 72, from which paper this and other values quoted here are taken).

$\dagger$ Solvents, Benzene, \&c.

$\mp$ Percentage on the lowest value.

$\$$ Omitting borax, where the value is exceptionally high.

II Chem. Soc. Trans. 1890. The values selected refer to solutions of the eame strength as those used by Raoult. The results with calcium nitrate and chloride are as yet unpublished. 


\begin{tabular}{|c|c|c|c|}
\hline Solvent. & Dissolved substance. & $\begin{array}{l}\text { Depres- } \\
\text { sion* }\end{array}$ & Variation*. \\
\hline $\begin{array}{c}\text { Tetrahydrate of sulphuric } \\
\text { acid. } \\
\text { Do. } \\
\text { Monohydrate of sulphuric } \\
\text { acid. } \\
\text { Do. } \\
\text { Sulphuric acid. } \\
\text { Do. } \\
\text { Hexahydrate of calcium } \\
\text { chloride. } \\
\text { Do. } \\
\text { Tetrahydrate of calcium } \\
\text { nitrate. } \\
\text { Do. }\end{array}$ & $\begin{array}{l}\text { Water. } \\
\text { Sulphuric acid. } \\
\text { Water. } \\
\text { Sulphuric acid. } \\
\text { Water. } \\
\text { Sulphuric anhydride. } \\
\text { Water. } \\
\text { Anhyd. calc. chlor. } \\
\text { Water. } \\
\text { Anhyd. ealc. nitrate. }\end{array}$ & $\left.\begin{array}{l}0.08 \\
0.04 \\
0.02 \\
0.01 \\
0.07 \\
0.42 \\
0.008 \\
0.010 \\
0.007 \\
0.015\end{array}\right\}$ & $\begin{array}{l}100 \\
500 \\
233\end{array}$ \\
\hline
\end{tabular}

As an instance of a similar character we may quote Heycock and Neville's determinations of the depression of the freezing-point of sodium by various metals $\uparrow$.

$$
\begin{aligned}
& \text { Metal added. Molec. depression. }
\end{aligned}
$$

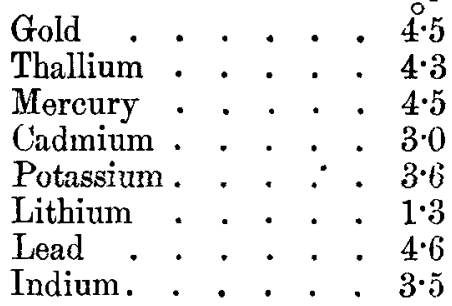

The variation here is 260 per cent.

If such variations are not too great to be attributed to an excess of two or three atmospheres' pressure (and I certainly think they are), they are undoubtedly too great to permit of a theory being founded on the assumption that they are constant.

It may be noted also that Heycock and Neville's determinations with indium, gold, and thallium extended to solutions as dilute as the gases from these metals would be (if their molecules are diatomic), and that even with these "ideal" solutions the variation amounted to 60 per cent.; had lithium and cadmium been similarly investigated we should, no doubt, have found as great a variation as that quoted above with the stronger solutions.

* Most of these values are but approximations.

$\dagger$ Chem. Soc. Trans. 1889 , p. $66 \%$. The values refer to solutions containing as near as possible one atom of the foreign metal to $100 \mathrm{Na}$. 


\section{Direction of the Deviations with Dissolved Substances which give Abnormal Values.}

The äbnormally low values (i.e. half values) which some dissolved substances give are attributed, as has been mentioned, to the polymerization of their acting molecules, and the abnormally high values which some solvents give are, in the same way, attributed to a polymerization of the solvent molecules. This view is accepted by both the supporters and the opponents of the osmotic pressure theory.

In the case of dissolved substances which give abnormally high values (i. e. double values), the supporters of the theory hold that these substances are dissociated into their ions, and in this view their opponents cannot agree with them.

The first point to settle, is whether there are any abnormally high values (given by dissolved substances), and it appears to me that there certainly are none.

In the case of the five organic solvents examined, the substances giving the higher and lower values are in the proportion of 100 to 16 , and here there can be (and is) no question as to which are the normal ones; even if in the case of water these proportions were reversed, it would be inconsistent to term the lower values the normal ones; but the proportions are actually not reversed, the substances giving bigh values being to those which give the lower ones in the proportion of 100 to 76 . I fail to see therefore what grounds there are for saying that there are any abnormally high (double) values at all, or what need there is for calling in such a theory as that of dissociation into ions *.

Indeed, there is a distinct difficulty, if not impossibility, in calling the lower values $\left(1^{\circ} \cdot 03\right)$ the normal ones; for the normal value with other liquids is $0^{\circ} .63$, and the excess in the case of water could only be explained by the water molecules being more complex than those of other liquids in the pro-

* Van't Hoff's statement as to Raoult's position respecting the high and low values of substances in water is certainly remarkable; he says (Phil. Mag. 1888, xxvi. p. 99), "Raoult did not discover the existence of so-called normal [meaning small] molecular depression of freezing-point and lowering of vapour-pressure until he investigated organic compounds; their behaviour is almost without exception regular." As a matter of fact, Raoult investigated organic substances first (Ann. Chim. Phys. 1883 [5] xxviii. p. 133), and when he subsequently (ibid. 1884 [6] xi. p. 81) found that inorganic substances gave higher values, he did not hesitate to call these latter the normal ones.

If we reverse the application of the word normal, we shall have to admit that of the 150 substances examined in water, not one gave an abnormally low value. A most improbable admission. 
portion of 1.03 to 0.63 ; in other words, that the water molecule is $1 \frac{1}{2} \mathrm{H}_{2} \mathrm{O}$, and that the atomic theory is wrong.

The theory of dissociation into ions is, for many reasons, inacceptable to most chemists, and its application to the results at present under discussion affords, I think, some of the strongest arguments against its acceptance.

If the higher values in the case of water are due to dissociation, we must conclude that all the stronger acids (e.g. hydrochloric, sulphuric, and nitric acids) are ne:arly entirely dissociated, whereas the weaker ones (e.g. hydrocyanic, sulphurous, and boric acids) are not so ; and similar conclusions must be drawn respecting the alkalies and salts. In fact, we shall be driven to conclude that the more stable the compound is the more easily is it dissociated, and that too by an agent, water, which has, ex lyypothesi, no action beyond the diluting effect of its mass. Is it possible to maintain that sulphurous acid exists intact in solution, while sulphuric acid, which is formed from it and molecular oxygen, with the evolution of $55,000 \mathrm{cal}^{*}$, and which must, therefore, be by so much the stabler body of the two, is entirely dissociated? Is it possible to maintain that hydrochloric acid is entirely dissociated at a pressure of three or four atmospheres when we know as a fact that it can exist undissociated at a pressure of only one atmosphere $\nmid$ ?

Indeed, it appears to me that if we acknowledge such a dissociation we must deny the principle of the conservation of energy. Thus, to take one instance out of many, the molecules of hydrogen and chlorine must $\ddagger$ be formed from their constituent atoms with a considerable development of heat, say $+x$ and $+y$ cal. respectively, and they react with each other to form $2 \mathrm{HCl}$ with a further development of $44,000 \mathrm{cal}$.; if this $2 \mathrm{HCl}$, when dissolved in water, be entirely dissociated into its atoms, it must absorb $44,000+x+y$ cal., whereas, as a matter of fact, it evolves 34,630 cal. : hence there has been a creation of $(78,630+x+y)$ cal. out of nothing,

* If atomic oxygen were taken, as it should be, the heat evolved would be much greater.

t In acetic acid hydrochloric acid is, according even to the supporters of the theory, not only not dissociated into its ions, but even not dissociated into its fundamental molecules, it being present as $2 \mathrm{HCl}$.

$\ddagger$ I think that we may say " must." If they were formed with absorption of heat it would mean that the atoms repel each other, and such atoms would, therefore, never combine. When we call a molecule endothermic, we merely mean that it is formed from its constituent atoms with a smaller development of heat than some other compound of the same atoms, not that it is formed from these atoms with an absorption of heat. 
and that, too, through the agency of the water, which is assumed to have no action at all.

\section{Influence of the Nature of the Solvent.}

It is found that the nature of the solvent, instead of being without influence on the results, as it should be according to the osmotic-pressure theory, is one of the main factors in determining them.

Thus, for instance, sulphuric and hydrochloric acids give the normal high values when dissolved in water, but solutions of the same strength in acetic acid show the abnormal halfvalues : formic and benzoic acids, methyl, ethyl, butyl, and amyl alcohols, as well as phenol, all give normal depressions with acetic acid, but abnormal ones with benzene. Many other instances of a similar character may he selected from Raoult's data, but none of them show the influence of the nature of the solvent in such a forcible manner as the following :-

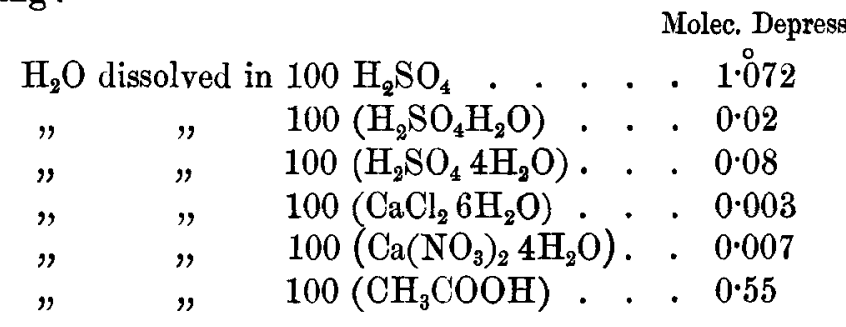

The variation of this constant (?) calculated on the smallest value amounts to 35,600 per cent. Again,

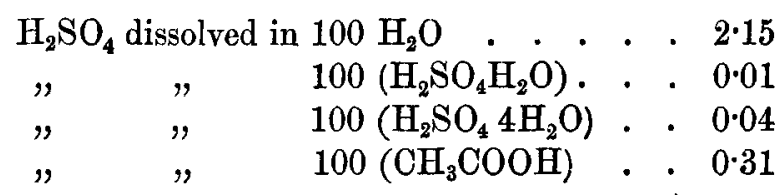

Extreme variation 21,400 per cent. Similarly,

$\mathrm{CaCl}_{2}$ dissolved in $100 \mathrm{H}_{2} \mathrm{O}$. . . . . 2.773

" " $100\left(\mathrm{CaCl}_{2} 6 \mathrm{H}_{2} \mathrm{O}\right)$. . 0.010

Variation 27,600 per cent.; and

$\mathrm{Ca}\left(\mathrm{NO}_{3}\right)_{2}$ dissolved in $100 \mathrm{H}_{2} \mathrm{O}$. . . . $\quad 2.50$

",$\quad 100 \mathrm{Ca}\left(\mathrm{NO}_{3}\right)_{2} 4 \mathrm{H}_{2} \mathrm{O} . \quad 0.015$

Variation 16,600 per cent. 
Such numbers can certainly not be accepted as constants, and the values are certainly largely dependent on the nature of the solvent*.

In the present instance the rariation cannot always bo taken as a proof of the ineorrectness of the osmotic-pressure theory, for it may be perfectly legitimate to attribute it sometimes to the various complexity of the molecules of the solvent. But we cannot, however, do so in all cases, as for instance that of formic \&c. acids in benzene and acetic acid, where the two solvents have been proved to act normally with the majority of dissolved substances. Yet, in any case, the absence of constancy means the absence of what would have been a strong argument in favour of the theory, and this absence must be felt all the more because there appears to be no simple numerical relationship between the very different values given above.

\section{Influence of Proportions taken with very Weak Solutions.}

My own recently published results (Chem. Soc. Trans. 1890, p. 3311) with sulphuric-acid solutions form, I believe, the only series of determinations as yet made which would, from their number and precision, be at all likely to settle whether the molecular depression is really constant or not with very weak solutions; and the results here can leave little doubt but that it is not so.

Between 0 and 9 per cent. solutions the results are represented by what would with rough determinations appear to be a single line of typical straightness. The deviations from straightness in regions below 4 per cent. (about $0.8 \mathrm{H}_{2} \mathrm{SO}_{4}$ to $100 \mathrm{H}_{2} \mathrm{O}$ ) are less than $0^{\circ} 02$, and would, therefore, not have been revealed by determinations such as have been made by other investigators. From 4 per cent. to 0 the determinations (each being the mean of several observations) which I made show mean error of $0^{\circ} .0008$ at most, and the number of points determined is about 80 ; and the results obtained leare no doubt but that the apparently straight line is really composed of four distinct lines, three of which are straight, meeting at (generally) well marked angles at the percentages of $1 \cdot 0$, $0 \cdot 35$, and 0.07 respectively.

The relative magnitude of these changes is best illustrated by drawing a straight line from the freezing-point of water

* Combining the variations due to different solvents with those due to different dissolved substances, we get a variation of 153,000 per cent. $\left(4^{0.6}\right.$ to $\left.0^{\circ} .003\right)$. 
to that of a 2.5 per cent. solution $\left(\mathrm{H}_{2} \mathrm{SO}_{4}\right.$ to $200 \mathrm{H}_{2} \mathrm{O}$; this was selected merely because at this percentage the diagram attains the highest relative point) and plotting out the deviations of the observed freezing-points from this line. The accompanying figure illustrates the result. The deviation

Deviation of the Freezing-points of weak solutions of Sulphuric Acid from regularity.

Deviation.

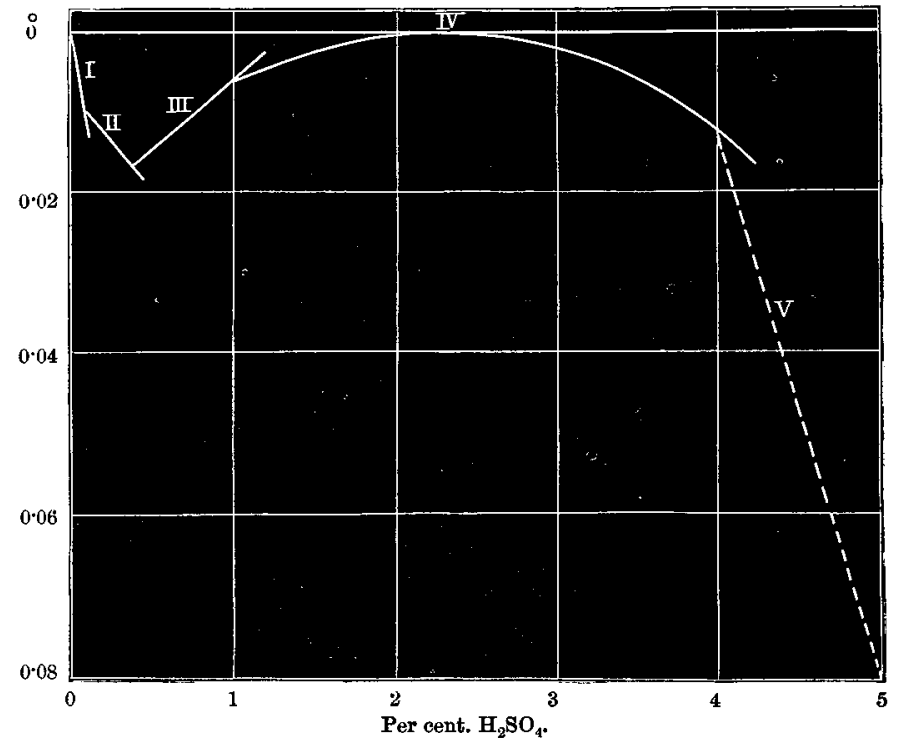

from straightness amounts to at least 20 times the mean experimental error, and 28 per cent. of the total depression. Even if we draw our straight line from a solution of 0.44 $\left(\cdot 08 \mathrm{H}_{2} \mathrm{SO}_{4}\right.$ to $100 \mathrm{H}_{2} \mathrm{O}$ ) per cent. strength-in which the sulphuric acid would be as much expanded as it would when a gas at ordinary pressures-the aberration, at 0.7 per cent., amounts to $0^{\circ} 008$, or 20 per cent. of the total depression.

The molecular depression calculated from these results, together with others obtained with stronger solutions, are given in the following table:- 
Depression of the Freezing-point of Water produced by the addition of Sulphuric Acid.

\begin{tabular}{|c|c|c|c|}
\hline Per cent. $\mathrm{H}_{2} \mathrm{SO}_{4}$. & $\begin{array}{c}\text { Mols. } \mathrm{H}_{2} \mathrm{SO}_{4} \text { to } \\
100 \mathrm{H}_{2} \mathrm{O} .\end{array}$ & F.-P. & $\begin{array}{l}\text { Molecular } \\
\text { depression. }\end{array}$ \\
\hline $\begin{array}{c}0 \cdot 068 \\
0 \cdot 3618 \\
0 \cdot 44 \\
1 \cdot 057 \\
2 \cdot 500 \\
4 \cdot 021 \\
6 \cdot 000 \\
8 \cdot 585 \\
18 \cdot 492 \\
29 \cdot 526 \\
37 \cdot 701\end{array}$ & $\begin{array}{c}0.0125 \\
0.0667 \\
0 \cdot 0811 \\
0.1961 \\
0.4708 \\
0 \cdot 7692 \\
1.1855 \\
1.724 \\
4.167 \\
7.692 \\
11 \cdot 111\end{array}$ & $\begin{array}{l}-0.0369 \\
=0.1580 \\
-0.1874 \\
=0.4214 \\
-0.9825 \\
-1 \cdot 600 \\
=2.520 \\
-3.456 \\
-11.83 \\
-34.00 \\
-72.63\end{array}$ & $\begin{array}{l}2 \cdot 95 * \\
2 \cdot 37 \\
2 \cdot 31 \\
2 \cdot 15 \\
2 \cdot 09 \\
2 \cdot 08 \\
2 \cdot 15 \\
2 \cdot 00 \\
2 \cdot 84 \\
3 \cdot 74 \\
6 \cdot 54\end{array}$ \\
\hline
\end{tabular}

The depression with solutions weaker than $\mathrm{H}_{2} \mathrm{SO}_{4}$ to 100 $\mathrm{H}_{2} \mathrm{O}$ varies between $2^{\circ} \cdot 08$ and $2^{\circ} \cdot 95,42$ per cent., and even between 0.44 and 0 per cent. it varies from $2^{\circ} .31$ to $2^{\circ} \cdot 95$, a variation of 28 per cent., numbers which can give no grounds whatever for the statement that the depression, even with these very weak solutions, is independent of the strength.

The only other determinations which, so far as I know, exist with solutions containing less than one dissolved molecule to 100 of the solvent, are those of Heycock and Neville (loc. sup. cit.) with certain alloys. Selections from those series which were most fully investigated supply the following data :-

\begin{tabular}{|c|c|c|}
\hline Solvent. & Dissolved substance. & Molecular depression. \\
\hline $\begin{array}{c}100 \mathrm{Na} \\
" \\
"\end{array}$ & $\begin{array}{l}0.114 \mathrm{Au} \\
0.296 ", \\
0.966 "\end{array}$ & $\begin{array}{l}5 \cdot 9 \\
4 \cdot 74 \\
4 \cdot 54\end{array}$ \\
\hline$"$ & $\begin{array}{l}0.097 \mathrm{Cd} \\
0.391 " \\
0.648 "\end{array}$ & $\begin{array}{l}3 \cdot 92 \\
3 \cdot 71 \\
3 \cdot 17 \uparrow\end{array}$ \\
\hline
\end{tabular}

* With still weaker solutiuns the molecular depression is somewhat greater: with a 0.005 per cent. solution $\left(.0009 \mathrm{H}_{2} \mathrm{SO}_{4}\right.$ to $\left.100 \mathrm{H}_{2} \mathrm{O}\right)$ the value found was $3^{\circ} \cdot 4$, but the total depression here is so small that I have not included it or similar values in the table.

$\dagger$ With thallium, mercury, sodium, and indium, the depression was more constant, but the data were less complete. 
Direction of the Deviations from Constancy with Stronger

\section{Solutions.}

According to the theory of osmotic pressure the proportionality between pressure (lowering of freezing-point) and amount of substance dissolved will hold good, as has been remarked, only for very weak solutions. With stronger solutions the dissolved molecules will be brought within the sphere of each other's attraction and will, therefore, exert an abnormally small pressure ; that is, they will lower the freezing-point of the solvent to an abnormally small extent*.

But in every case at present known exactly the reverse is the case. Stronger solutions exhibit an abnormally large depression, and the freezing-points fall at an increasing instead of a diminishing rate. The table given above illustrates to what extent this takes place in the case of solutions of sulphuric acid in water, the molecular depression increasing from $2^{\circ} .08$ to $6^{\circ} .54$ (213 per cent.), and the examination of six other curves from the sulphuric-acid series, and two of a series with calcium nitrate, supplies us with eight other instances of a similar character. The results may be summarized thus :-

\begin{tabular}{|c|c|c|c|}
\hline Solvent. & Dissolved substance. & Molec. depression. & Increase. \\
\hline $\begin{array}{l}100 \mathrm{H}_{2} \mathrm{SO}_{4} \\
100 \mathrm{H}_{2} \mathrm{SO}_{1} \\
100\left(\mathrm{H}_{2} \mathrm{SO}_{4} \mathrm{H}_{2} \mathrm{O}\right) \\
100\left(\mathrm{H}_{2} \mathrm{SO}_{4} \mathrm{H}_{2} \mathrm{O}\right) \\
100\left(\mathrm{H}_{2} \mathrm{SO}_{4} 4 \mathrm{H}_{2} \mathrm{O}\right) \\
100\left(\mathrm{H}_{2} \mathrm{SO}_{4} 4 \mathrm{H}_{2} \mathrm{O}\right) \\
100\left(\mathrm{Ca}\left(\mathrm{NO}_{3}\right)_{2} 4 \mathrm{H}_{2} \mathrm{O}\right) \\
100\left(\mathrm{Ca}\left(\mathrm{NO}_{3}\right)_{4} 4 \mathrm{H}_{2} \mathrm{O}\right)\end{array}$ & $\begin{array}{l}1 \text { to } 33 \mathrm{H}_{2} \mathrm{O} \\
1 \text { to } 5 \cdot 8 \mathrm{SO}_{3} \\
1 \text { to } 50 \mathrm{H}_{2} \mathrm{O} \\
1 \text { to } 50 \mathrm{H}_{2} \mathrm{SO}_{4} \\
1 \text { to } 400 \mathrm{H}_{2} \mathrm{O}^{7} \\
5 \text { to } 60 \mathrm{H}_{2} \mathrm{SO}_{4} \\
1 \text { to } 150 \mathrm{H}_{2} \mathrm{O}^{-} \\
1 \text { to } 33 \mathrm{Ca}\left(\mathrm{NO}_{3}\right)_{2}\end{array}$ & $\begin{array}{l}1.072 \text { to } 1.253 \\
0.422 \text { to } 0.634 \\
0.02 \text { to } 0.31 \\
0.01 \text { to } 0.197 \\
0.078 \text { to } 0.108 \\
0.27 \text { to } 0.42 \\
0.007 \text { to } 0.326 \\
0.015 \text { to } 0.179\end{array}$ & 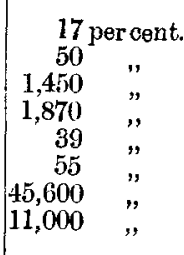 \\
\hline
\end{tabular}

It is true that these results bave only recently been placed at the disposal of the supporters of the osmotic-pressure theory, but it is otherwise with the following values in the case of alcohol (Raoult, Compt. Rend. xc. p. 863) and calcium chloride (Hammerl, Wien. Sitzungsber. lxxviii. p. 59) \$:-

* The same will hold good if we attribute dissolution to the balancing of the physical attractions of (1) solvent for solvent molecules, (2) dissolred for dissolved molecules, and (3) solvent for dissolved molecules. The stronger the solution the greater will be (2), and, consequently, the less will (1) be counterbalanced.

$\uparrow$ With $60 \mathrm{H}_{2} \mathrm{O}$ the depression is $0^{\circ} 067$, so that it first decreases and then increases.

With 1 mol. $\mathrm{H}_{2} \mathrm{SO}_{4}$ it is $0^{\circ} \cdot 40$.

In each case I give the values as determined from my own results, but these are in good accord with those referred to above. 


\begin{tabular}{|c|c|c|c|}
\hline Solvent. & Dissolved substance. & Molec. depression. & Increase. \\
\hline $\begin{array}{l}100 \mathrm{H}_{2} \mathrm{O} \\
100\left(\mathrm{CaCl}_{2} 6 \mathrm{H}_{2} \mathrm{O}\right) \\
100 \mathrm{H}_{2} \mathrm{O}\end{array}$ & $\begin{array}{l}1 \text { to } 7 \mathrm{CaCl}_{2} \\
1 \text { to } 800 \mathrm{H}_{2} \mathrm{O} \\
1 \text { to } 13 \mathrm{C}_{2} \mathrm{H}_{6} \mathrm{O}\end{array}$ & $\begin{array}{l}2.773 \text { to } 6.9 \\
0.003 \text { to } 0.099 \\
1.11 \text { to } 1.18\end{array}$ & $\begin{array}{c}150 \text { per cent. } \\
3200 " \\
6\end{array}$ \\
\hline
\end{tabular}

The increase in the case of alcohol is small, but still there is an increase, and not a decrease; while in the case of water in the hydrate of calcium chloride the increase is almost the greatest at present known.

\section{Irregularity of the Deviations with Weak Solutions.}

That the deviations from constancy are not regular, and are not even always in the same direction, will be seen on referring to the results with sulphuric acid dissolved in water (p. 499); the depression in the freezing-point of the tetrahydrate, both by water and sulphuric acid, supplying two other instances of a similar character.

Since every fact which can be used to test whether the theory of osmotic pressure is a true explanation of the nature and behaviour of solutions, either fails to give any evidence in its favour, or else gives evidence directly opposed to it-evidence, often, of the strongest possible character-this theory can certainly not yet be regarded as established.

LVII. A Mercury-still for the Rapid Distillation of Mercury in a Vacuum. By Frederick J. Sмith, M.A., Millard Lecturer in Mechanics and Physics, Trinity College, Oxjord*. W
apparatus, a large portion of it when vaporized, on reaching the internal domed surface of the bulb in which the operation is conducted, forms itself into minute spheres, which grow heavy and run down the inside of the bulb; and only a small quantity of the metal finds its way into the central tube, from which it is caught for use.

The advantage of the new form of vacuum mercury-still, of which I venture to give an account, is that all the mercury, which condenses in the head of the bulb, is prevented by its shape from returning to the mercury from which it has been separated by heat. This is not the case in the mercury-still of Weinhold, or Clark, or in those stills in which only the mercury which collects in the eduction-tube is caught, as in

* Communicated by the Author.

Phil. Mag. S. 5. Vol. 29. No. 181. June 1890. 2 Q 